\title{
Моделирование напряженно-деформированного состояния завихрителя вихревой горелки
}

\author{
В. В. Афтанюк, С. К. Бандуркин, С. Е. Жолудь
}

Одесская государственная академия строительства и архитектуры, ул. Дидрихсона 4, г. Одесса, 65000, Украина

\begin{abstract}
Изложены методика и результаты численного моделирования напряженно-деформированного состояния лопаток завихрителя вихревой горелки, разработанной для модернизации отопительных котлов. Особенностью предложенной горелки является конструкция закручивающего устройства (завихрителя), которое представляет собой корпус с установленными внутрь двумя рядами встречных направляющих лопаток. Это позволяет достичь увеличения турбулизации и закручивания потока и, как следствие, улучшает процесс горения, а также значительно расширяет диапазон регулирования геометрии и параметров факела. Целью численного моделирования завихрителей вихревой горелки является проверка надежности конструкции под действием гидродинамических сил в процессе эксплуатации. Сформулирована математическая постановка задачи, описана методика моделирования с помощью метода конечных элементов. Разработана твердотельная модель завихрителя вихревой горелки. Твердотельная модель разбита на два моделирующих элемента: внешний и внутренний завихрители. Определены поверхности, на которые воздействуют нагрузки и поверхности, находящиеся в относительном покое. Проведен анализ механизмов и закономерностей повреждения лопаток, полей остаточных напряжений. Приведены полученные в результате моделирования количественные оценки параметров надежности лопаток вихревого завихрителя.
\end{abstract}

Ключевые слова: Горелки отопительных котлов; Лопатки завихрителей; Остаточные напряжения в лопатках завихрителей.

\section{Моделювання напружено-деформованого стану завихрувача вихрового пальника}

\section{В. В. Афтанюк, С. К. Бандуркін, С. Є. Жолудь}

Одеська державна академія будівництва та архітектури, вул. Дідріхсона 4, м. Одеса, 65000, Україна

\begin{abstract}
Викладені методика і результати чисельного моделювання напружено-деформованого стану лопаток завихрувача вихрового пальника, що розроблений для модернізачії опалювальних котлів. Особливістю запропонованого пальника є конструкція закручуючого пристрою (завихрувача), який представляє собою корпус з встановленими всередину двома рядами зустрічних напрямних лопаток. Це дозволяє досягти збільшення турбулізації і закручування потоку $i$, як наслідок, покращує процес горіння, а також значно розширює діапазон регулювання геометрії $і$ параметрів факела. Метою чисельного моделювання завихрувачів вихрового пальника є перевірка надійності конструкції під дією гідродинамічних сил в процесі експлуатації. Срормульована математична постановка задачі, описана методика моделювання за допомогою методу кінцевих елементів. Розроблена твердотільна модель завихрувача вихрового пальника. Твердотільна модель розбита на два моделюючих елемента: зовнішній і внутрішній завихрувачі. Визначені поверхні, на які впливають навантаження і поверхні, які знаходяться у відносному спокої. Проведено аналіз механізмів і закономірностей пошкодження лопаток, полів залишкових напружень. Наведені отримані в результаті моделювання кількісні оцінки параметрів надійності лопаток вихрового завихрувача.
\end{abstract}

Ключові слова: Пальники опалювальних котлів; Лопатки завихрувачів; Залишкові напруги в лопатках завихрувачів.

DOI: http://dx.doi.org/10.15673/ret.v53i1.541

(C) The Author(s) 2017. This article is an open access publication

This work is licensed under the Creative Commons Attribution 4.0 International License (CC BY) http://creativecommons.org/licenses/by/4.0/ 


\section{Введение}

Развитие энергетики требует при проектировании энергетического оборудования использования точных автоматизированных методов расчета. В связи с этим актуальной задачей является автоматизация моделирования и анализа напряженно-деформированного состояния элементов котельного оборудования.

Для модернизации водотрубных котлов была предложена конструкция вихревой горелки [1]. Особенностью предложенной горелки является конструкция закручивающего устройства (завихрителя), которое представляет собой корпус с установленными внутрь двумя рядами встречных направляющих лопаток (рисунок 1). Это позволяет достичь увеличения турбулизации и закручивания потока и, как следствие, улучшает процесс горения, а также значительно расширяет диапазон регулирования геометрии и параметров факела.

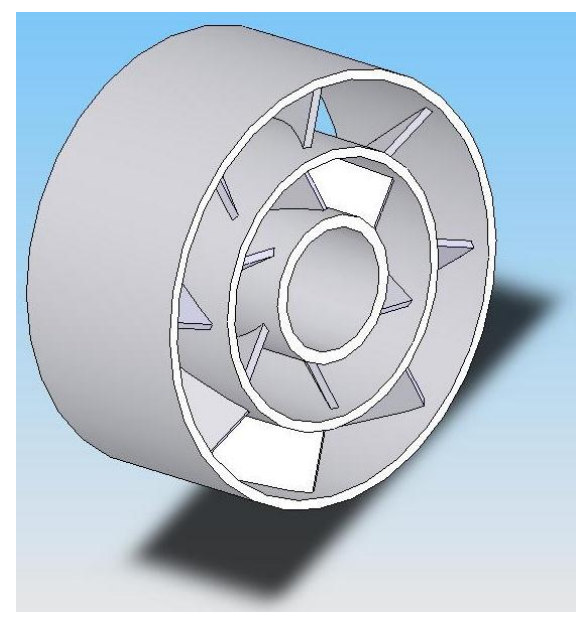

$$
\begin{gathered}
\text { Рисунок } 1 \text { - Твердотельная модель } \\
\text { завихрителя [1] }
\end{gathered}
$$

\section{1 Анализ проблемы моделирования напря- женно-деформированного состояния деталей машин}

Промышленное внедрение предложенного конструктивного решения вихревой горелки требует выполнения комплекса исследований с целью определения прочностных характеристик лопастей закручивающего устройства (завихрителя).

Прочность закручивающего устройства с лопастями определяет возможность получения высоких параметров работы горелки, обеспечивает необходимый срок службы.

С точки зрения прочности, наиболее уязвимой частью завихрителя горелки являются лопасти.

В процессе эксплуатации лопасти завихрителя находятся под воздействием гидродинамических сил в сочетании с высокой температурой, поэтому конструкция завихрителя должна отвечать условиям прочности от аэроупругих колебаний.
Для расчета прочности лопастей в турбомашиностроении используют два основных подхода.

Первый представляет собой метод расчета общей прочности по балочной теории. В этом случае лопасть представляется в виде заделанного на конце консольного прямого стержня с переменной площадью поперечных сечений. В процессе расчета проверяется выполнение условия статической прочности [2].

Второй подход основывается на использовании метода конечных элементов (МКЭ). МКЭ основан на дискретизации объекта для решения уравнений механики сплошной среды. При этом предполагается, что эти соотношения выполняются в пределах каждой из элементарных областей [3].

Исследование колебаний лопастей завихрителя вихревой горелки позволяет определить места с наибольшими эквивалентными напряжениями и, следовательно, наиболее вероятные очаги разрушения, места изменения рабочих условий безопасной эксплуатации.

\section{2 Расчет моделирования напряженно-дефор- мированного состояния завихрителя}

Используя комплекс программ [3], смоделировано напряженно-деформированное состояние лопастей завихрителя вихревой горелки.

Алгоритм моделирования напряженнодеформированного состояния включает следующие этапы:

1) Создание твердотельной модели.

2) Задание материала завихрителя.

3) Определение ограничений.

4) Задание нагрузок, приложенных к поверхностям.

5) Анализ напряженно-деформированного состояния.

6) Визуализация результатов моделирования.

Первым (важным) этапом моделирования является создание твердотельной трехмерной модели завихрителя.

Системы трехмерного геометрического моделирования [3] позволяют решить проблемы, возникающие при исследованиях физических моделей.

Твердотельная трехмерная (визуальная) модель выглядит аналогично физической, но является нематериальной. Такая модель сохраняется в памяти компьютера совместно со своим математическим описанием. Благодаря этому возможно устранение основного недостатка физической модели - проведения измерений для последующего прототипирования или серийного производства [4].

Представленный на рисунке 1 завихритель имеет сложную конструкцию, которую для обеспечения корректности расчетов рационально разбить на два элемента: внешний (рисунок 2, а) и внутренний завихрители (рисунок 2, б). 


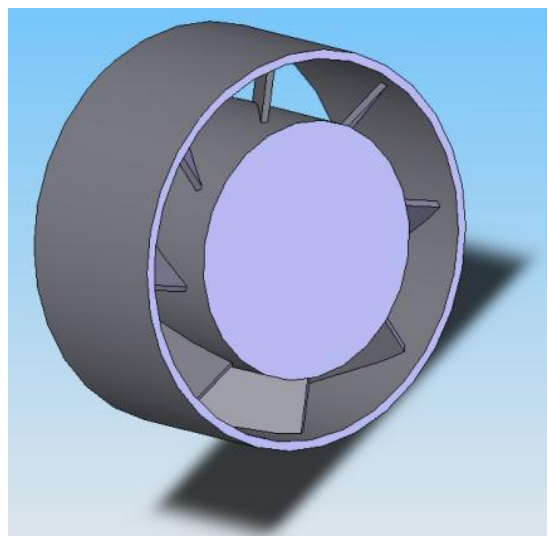

a)

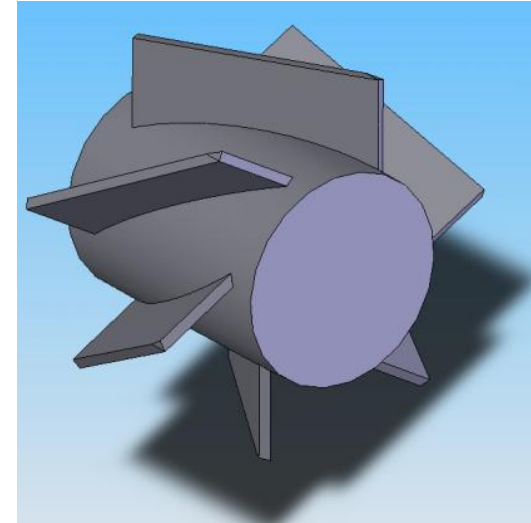

б)

Рисунок 2 - Твердотельные трехмерные модели завихрителей вихревой горелки:

а) внешний завихритель; б) внутренний завихритель.

На следующем этапе работы был проведен анализ напряженно-деформированного состояния моделей с помощью компьютерного моделирования в среде COSMOSXpress [3].

Расчеты, проводимые в COSMOSXpress, основаны на линейном статическом анализе в предположении, что материал является анизотропным.

Линейный статический анализ в COSMOSXpress предполагает следующие допущения [3]:

1) линейное поведение материала в соответствии с законом Гука;

2) индуцированные смещения являются достаточно небольшими, чтобы не учитывать изменения в жесткости в результате нагрузки;

3) динамические эффекты не учитываются, т.к. нагрузки прикладываются медленно.

Для расчетов принят материал из библиотеки

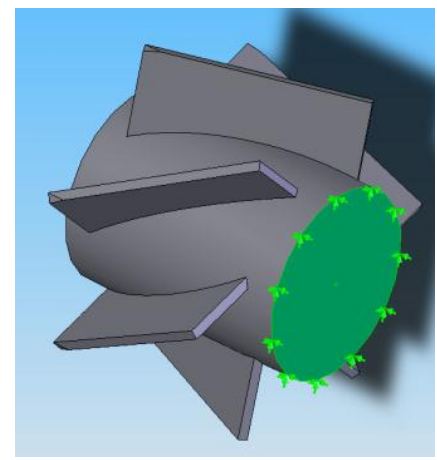

a)

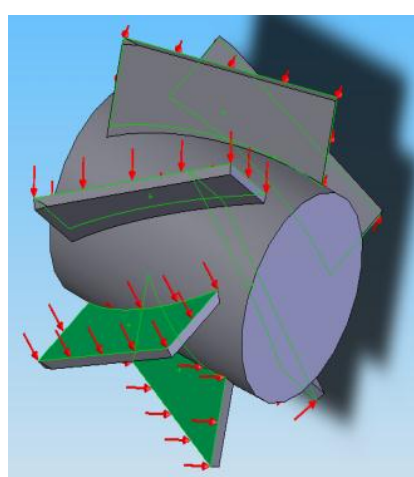

б)

SolidWorks с характеристиками:

- имя материала - легированная сталь;

- тип модели материала - линейный, упругий, изотропный;

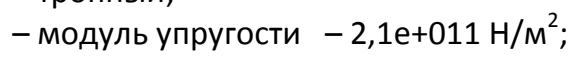

- коэффициент Пуассона - 0,28;

- модуль сдвига - 7,9е+010 H/M

- массовая плотность $-7700 \mathrm{kг} / \mathrm{m}^{3}$;

- коэффициент теплового расширения - 1,3e-5 $\mathrm{K}^{-1}$;

- теплопроводность - $50 \mathrm{BT} /(\mathrm{M} \cdot \mathrm{K})$;

- удельная теплоемкость - 460 Дж / (кг·К).

Для проведения дальнейших расчетов были выбраны поверхности, находящиеся в «относительно неподвижном» состоянии по отношению к воздействующим нагрузкам, затем определены поверхности и грани лопастей, на которые воздействуют силы гидродинамического давления (рисунок 3).

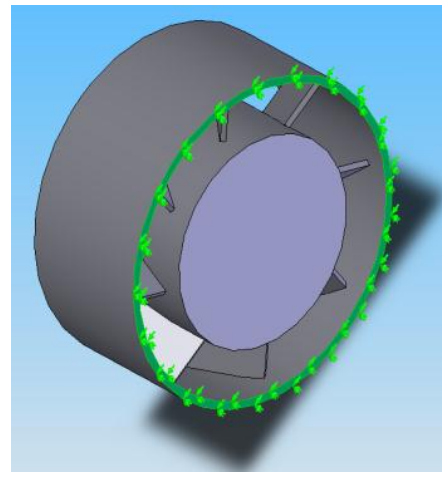

B)

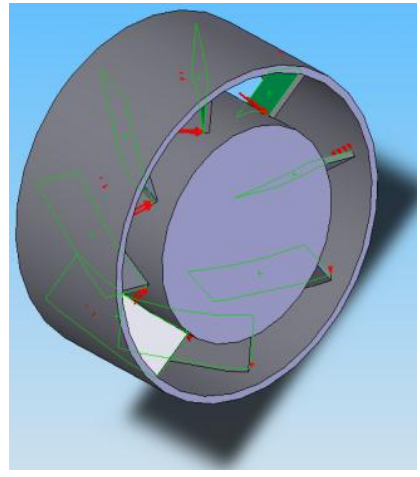

г)

Рисунок 3 - Модель внутреннего $(a, 6)$ и внешнего $(6,2)$ завихрителей с наложением ограничений и нагрузки: $a$ - ограничения во внутреннем завихрителе; 6 - нагрузка на внутренний завихритель; в - ограничения во внешнем завихрителе; г - нагрузка на внешний завихритель;

Осевая нагрузка на лопасти определялась приближенно по зависимости [5]:

$$
P=S_{\pi} \cdot \gamma \cdot H,
$$

где $S_{\text {л }}$ - площадь поверхности лопаток, $\mathrm{M}^{2} ; \gamma$ - удельный вес перемещаемой среды, $\mathrm{H} / \mathrm{M}^{3} ; \mathrm{H}$ - давление на входе в завихритель, м.
В результате проведения расчетов модели получена визуализированная информация по:

- распределению усилий в модели (рисунок 4);

- распределению смещений в модели (рисунок 5);

- конфигурации деформированной формы модели (рисунок 6). 


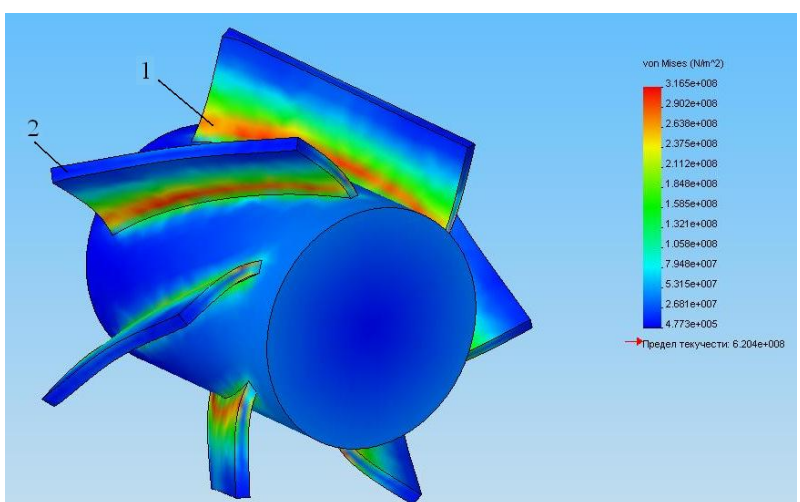

a)

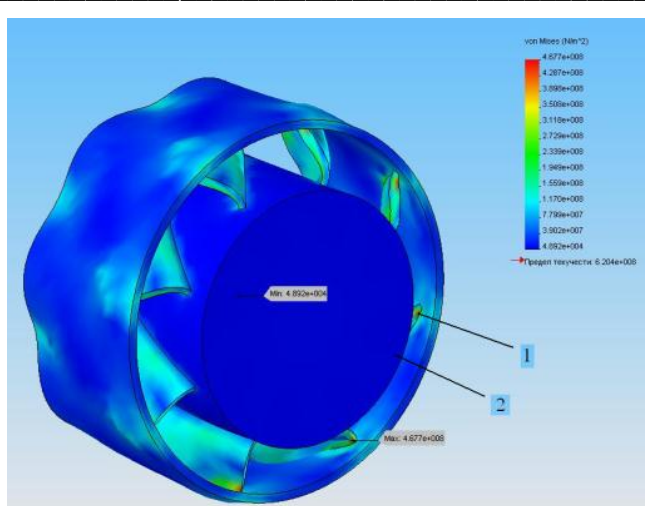

б)

Рисунок 4 - Эпюра распределения усилий в завихрителях: а - внутренний; б - внешний (1 - участки в которых возникают наибольшие усилия сопротивления при деформации модели; 2 - участки с наименьшими усилиями сопротивления при деформации модели).

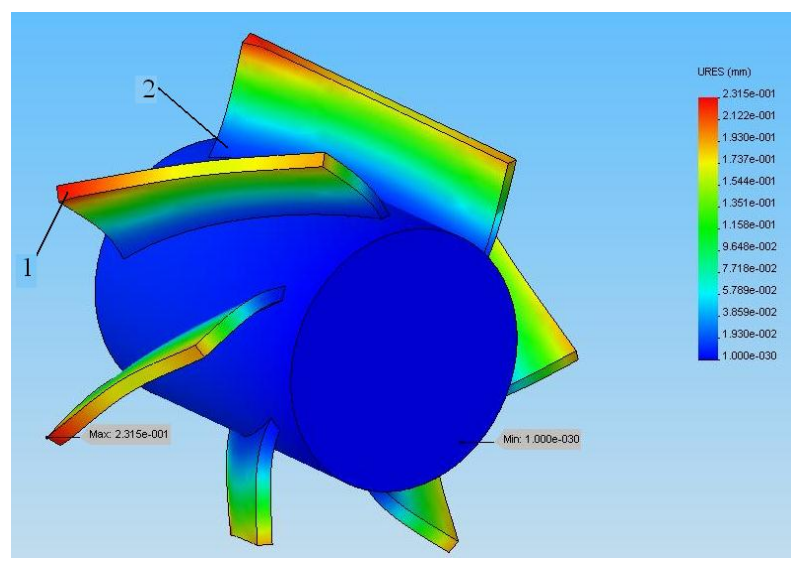

a)

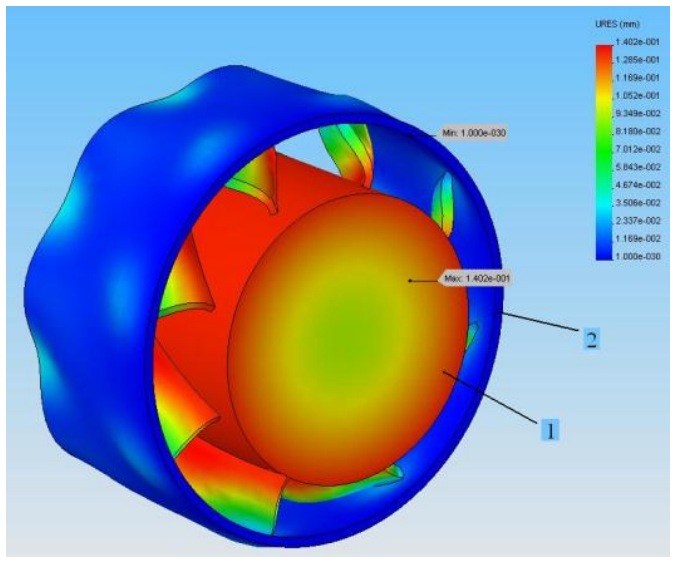

б)

Рисунок 5 - Эпюра смещений в завихрителях

(1 - участки в которых возникают наибольшие смещения от гидродинамической нагрузки; 2 - участки с наименьшими смещениями от гидродинамической нагрузки)

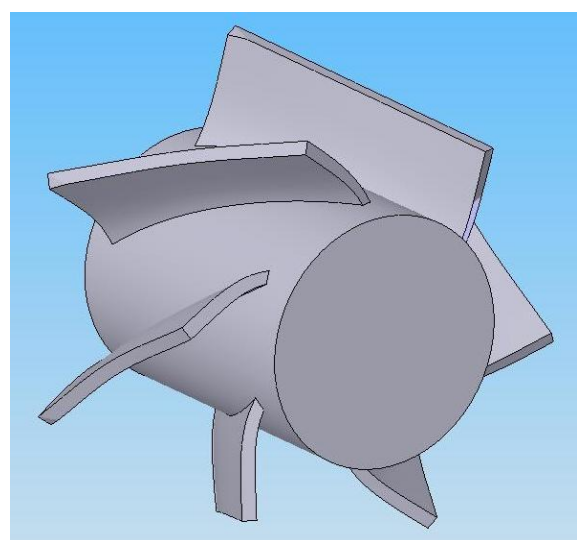

a)

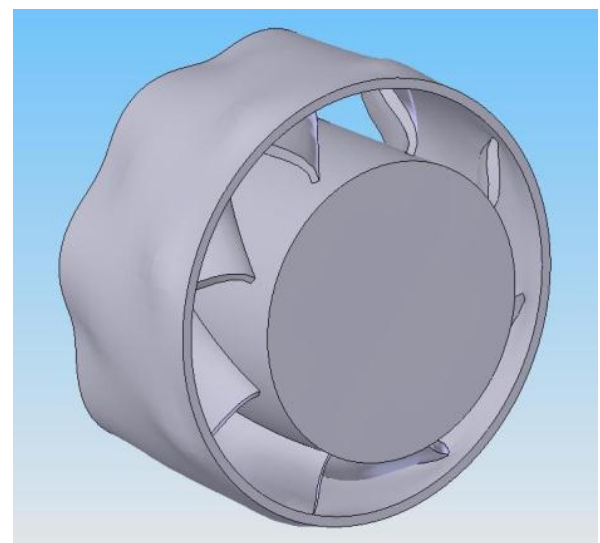

б)

Рисунок 6 - Деформированная форма моделей завихрителей: $a-$ внутренний завихритель; $\sigma$ - внешний завихритель.

\section{Выводы}

1. Разработаны твердотельные модели завихрителей вихревой горелки по [1], которые позволяют про- водить численное моделирование надежности лопастей завихрителей.

2. Проведено моделирование напряженнодеформированного состояния лопастей завихрителей 
под действием гиродинамических сил в среде COSMOSXpress. В расчетах использована расчетная сетка из элементов размером 6,3324 мм, количество элементов - 8999, количество узлов -14305.

3. Анализ эпюр позволил на поверхностях лопастей определить зоны, в которых наблюдаются максимальные усилия и смещения.

4. Результаты проверки проектирования показали достаточную надежность конструкции для безаварийной эксплуатации для всех граней модели, коэффициент запаса прочности больше 1.

\section{Литература}

1. Пат. 49720. Україна, МПК (2009) F23D 17/00. Вихровий пальник для спалювання газоподібного та рідкого палива. Автори: Афтанюк В.В., Бандуркін С. К., Поляков
А.Л., Попов Ю.Г. Заявл. 09.11. 2009; опубл. 11.05.2010, Бюл. №9.

2. Бойко А.В., Гаркуша А.В. Аэродинамика проточной части паровых и газовых турбин: расчеты, исследования, оптимизация, проектирование. Харьков, ХГПУ, 1999. - $390 \mathrm{c}$.

3. SolidWorks. Компьютерное моделирование в инженерной практике / Алямовский А.А., Собачкин А.А., Одинцов Е.В., Харитонович А.И., Пономарев Н.Б. - СПб.: БХВ-Петербург, 2005. - 800 с.

4. Трехмерное геометрическое моделирование. Учебн. Пособие / Смирнов А. А. - М.: Изд-во МГТУ им. Н.Э. Баумана, 2008. -40 с.

5. Справочное пособие по гидравлике, гидромашинам и гидроприводам/ Вильнер Я.М., Ковалев Я.Т., Некрасов Б.Б. Под ред. Б.Б. Некрасова. - Минск, «Вышэйш. школа», 1976, 416 с.

Отримана в редакції 17.11.2016, прийнята до друку 07.02.2017

\title{
Simulation of Stress-Strain State of the Vortex Burner's Swirler
}

\author{
V. V. Aftaniuk, S. K. Bandurkin, S. E. Zholud
}

Odessa State Academy of Civil Engineering and Architecture, 4 Didrihsona st., Odessa, 65029, Ukraine

The technique and results of numerical simulation of the stress-strain state of the blades of the vortex burner swirler developed for the modernization of heating boilers are outlined. For the modernization of water-tube boilers, the design of the vortex burner was proposed. A feature of the proposed burner is the design of a swirl device (), which is a body with inwardly mounted two rows of opposing guide blades. This permits to increase the turbulence and twisting of the flow and, as a result, improves the combustion process, and also considerably extends the range of geometry regulation and flame parameters. The purpose of swirlers numerical simulation is to check the structure reliability under the influence of hydrodynamic forces during operation. The study of the oscillations of the vortex burner blades makes it possible to determine the places with the greatest equivalent stresses, and, consequently, the most probable foci of failure, the place of change in the operating conditions of safe operation. The mathematical formulation of the problem is formulated; the method of modeling with the help of the finite element method is described. To carry out the simulation, specialized computer programs were used. A solid model of a vortex burner was developed. The solid model is divided into two modeling elements, external and internal. The surfaces on which the loads and surfaces are in relative rest were determined. The loads on the vortex blades were determined from the empirical relationships given in the specialized literature. The analysis of the mechanisms and regularities of damage to the blades, residual stress fields was carried out. The quantitative estimates of the reliability parameters of vortex blades obtained as a result of modeling are presented. Analysis of the diagrams made it possible to determine the zones (on the surfaces of the blades) in which maximum forces and displacements are observed. The results of the design check showed sufficient design reliability for accident-free operation, for all faces of the model, the safety factor is greater than 1.

Keywords: Burners of Heating Boilers, Vortex Blades, Residual Stresses in Vortex Blades.

\section{References}

1. Patent 49720. Ukraine, MPK (2009) F23D 17/00. Vihrovyi palnik dlia spaliuvannia gazopodibnogo ta ridkogo palyva. Aftanyuk V.V., Bandurkln S. K., Polyakov A.L., Popov Yu.G. Zayavl. 09.11. 2009; publ. 11.05.2010, Biul. No.9. (in Ukrainian)

2. Boyko, A. V., Garkusha, A. V. (1999) Aerodinamika protochnoy chasti parovyih i gazovyih turbin: raschetyi, issledovaniya, optimizatsiya, proektirovanie. Harkov, HGPU, 390 p. (in Russian)
3. Alyamovskiy, A. A., Sobachkin, A. A., Odintsov, E. V., Haritonovich, A. I., Ponomarev, N. B. (2005) SolidWorks. Kompiuternoe modelirovanie $v$ inzhenernoi praktike. SPb., BHV-Peterburg,, 800 p. (in Russian)

4. Smirnov, A. A. (2008) Trekhmernoe geometricheskoe modelirovanie. MGTU, 40 p. (in Russian)

5. Vilner, Ya. M., Kovalev, Ya. T., Nekrasov, B. B. (1976) Spravochnoe posobie po gidravlike, gidromashinam $i$ gidroprivodam, 416 p. (in Russian)

Received 17 November 2016 Approved 07 February 2017 Available in Internet 17 March 2017 